\title{
A functional study of the esophagus in patients with non-cardiac chest pain and dysphagia
}

\section{ESOPHAGUS}

Roberto Gullo', Angela Inviati', Piero Luigi Almasio², Valentina Di Paola', Silvia Di Giovanni', Gregorio Scerrino', Gaspare Gulotta', Sebastiano Bonventre'

'Department of Surgical and Oncological Sciences, Azienda Ospedaliera Universitaria "P. Giaccone", Palermo, Italy

${ }^{2}$ Gastrointestinal \& Liver Unit, Azienda Ospedaliera Universitaria "P. Giaccone", Palermo, Italy

\section{ABSTRACT}

Background/Aims: Nutcracker esophagus and non-specific motility disorders are the main causes of non-cardiac chest pain (NCCP), with gastroesophageal reflux in $60 \%$ of cases. Achalasia and diffuse esophageal spasm are the most frequent anomalies described in patients with dysphagia. The goal of this study was to evaluate the occurrence of esophageal body and lower esophageal sphincter motor abnormalities in patients with dysphagia, NCCP, or both.

Materials and Methods: This study is a retrospective analysis of 716 patients with NCCP and/or dysphagia tested between January 1994 and December 2010. 1023 functional studies were performed, 707 of which were esophageal manometries, 225 esophageal pH-meters, and 44 bilimetries. We divided the patients into three groups: group 1 was composed of patients affected with dysphagia, group 2 with NCCP and group 3 with NCCP and dysphagia.

Results: Manometric anomalies were detected in $84.4 \%$ of cases $(p<0.001)$. The most frequent esophageal motility alteration was achalasia (36\%). The lower esophageal sphincter was normal in $45.9 \%$ of patients $(p<0.001)$. In all 3 groups, 80.9\%, 98.8\%, and 93.8, respectively, of patients showed normal upper esophageal sphincter ( $p=0.005)$.

Conclusion: Our data differs from those of other studies because they were collected from and analyzed by a single tertiary level referral center by a single examiner. This could have eliminated the variability found in different hands and different experiences. The high percentage of symptomatic patients with non-pathologic esophageal motility pattern suggests an unclear origin of the disease, with possible neuromuscular involvement. As a result, these patients may need more-detailed diagnostic studies.

Keywords: Dysphagia, non-cardiac chest pain, gastroesophageal reflux, esophageal dyskinesia

\section{INTRODUCTION}

Swallowing is a very complex process, and involves more than 26 muscles and 5 cranial nerves (V-VIIIX-X-XII) that control facial, palatine, suprahyoid and pharyngeal structures coordinated by the cerebellum $(1,2)$. Clinically, esophageal motor disorders often cause symptoms such as dysphagia and chest pain.

The prevalence of dysphagia in the general population is between $7 \%$ and $10 \%$ of adults, with no gender difference, while the incidence increases with age (3-5).

We recognize two types of dysphagia, the causes of which can be functional or anatomical. Oropharyngeal- dysphagia is often due to either neuromuscular diseases, anatomical abnormalities, lower esophageal sphincter (LES) anomalies, or esophageal-dysphagia. The latter can arise primitively, as in cases of achalasia, diffuse esophageal spasm, nonspecific motor abnormalities, nutcracker, and hypertensive LES, or can be secondary to obstructing lesions (stenosis or neoplasm), collagen vascular diseases, neuromuscular or endocrinemetabolic diseases, or gastroesophageal reflux disease (GERD) (6).

An intermittent moderate dysphagia due to ineffective esophageal contraction is relatively common, particu-

Address for Correspondence: Inviati Angela, Department of Surgical and Oncological Sciences, Azienda Ospedaliera Universitaria "P.

Giaccone", Palermo, Italy

E-mail: surgeryangela@hotmail.it

Received: July 23, 2013

Accepted: August 29, 2013

(c) Copyright 2015 by The Turkish Society of Gastroenterology • Available online at www.turkjgastroenterol.org • DOI: 10.5152/tjg.2015.5865 
larly in patients with GERD. Several manometric anomalies in patients with dysphagia have been described in the literature, including achalasia, diffuse esophageal spasm, hypertensive LES, nutcracker, and nonspecific motility disorders. Fass reported that the alterations most frequently found in patients with dysphagia are ineffective peristalsis (27\%), followed by hypotensive lower esophageal sphincter (18\%), achalasia (18\%) and non-specific esophageal motility disorder $(14 \%)(7,8)$.

According to the 2002 definition by the American Gastroenterological Association, non-cardiac chest pain (NCCP) is an angina-like retrosternal recurrent pain of non-cardiac origin. GERD is the most common contributing factor for chest pain. It is estimated that at least $25 \%$ of the general population have an episode of non-cardiac chest pain at least once in their lives (9). In these patients, a cardiac etiology is found in only $11-45 \%$ of cases, and only after significant costs to public health, and high social costs in terms of lost work days (10).

Esophageal diseases are the main causes of NCCP, and many studies have shown an association between GERD and NCCP. However, association does not confer causality, even if it has been demonstrated in $46-69 \%$ of NCCP patients. In fact, DeMeester et al. found that $46 \%$ of patients had chest pain associated with an acid reflux event as documented during $\mathrm{pH}$ testing. Stahl et al. found an association between chest pain and an abnormal pH test in $69.2 \%$ of 13 consecutive NCCP patients $(11,12)$.

A number of anomalies have been described in esophageal patients with NCCP. Katz et al. found an incidence of abnormal esophageal motility in $30 \%$ of patients with NCCP, with nutcracker esophagus the most commonly documented esophageal motility abnormality (14.4\%). Katz et al. found nonspecific esophageal motor disorders in $10.8 \%$ of their patients (13). Patti et al. found nutcracker esophagus in 41 of 397 NCCP patients (80\%), hypertensive lower esophageal sphincter 2 of the 397 (1\%), diffuse esophageal spasm in 49 (12\%), and achalasia in $305(77 \%)$ (14).

The aim of our study was to evaluate the distribution of esophageal motor abnormalities in patients with dysphagia, NCCP, or both.

\section{MATERIALS AND METHODS}

This study is a retrospective analysis of data on 716 patients with non-cardiac chest pain and/or dysphagia seen between January 1994 and December 2010 at the University of Palermo's Digestive Motility Department. All patients underwent upper endoscopy: in case of evidence esophagitis or esophageal obstruction patients were excluded.

\section{Esophageal manometry}

Medications that interfere with esophageal motility (calcium channel blockers, nitrates) were discontinued 3 days before the study. Patients were studied after an overnight fast by using an MMS 200 NARCO BYO SYSTEM manometer with 8 electrodes connected to an INTERNATIONAL BIOMEDICAL model 745-0100 pneumo-hydraulic capillary infusion system with 8 perfusional channels. ARNDORFER or MARQUAT multilumen manometric probes were used in various combinations with OPEN END TIP provided with 6 or 8 helical side-holes spaced 5 $\mathrm{cm}$ from each other. All probes were graduated (intervals of at least $1 \mathrm{~cm}$ ) to allow measurements of the catheter's depth and the length of the sphincter. Position, pressure, length, and relaxation of the LES were measured by using the dynamic pullthrough technique (normal LES pressure, 12-30 $\mathrm{mmHg}$ ). LES relaxation in response to swallowing was classified as complete when the LES pressure decreased to the gastric baseline pressure, absent when it did not change, and incomplete when it decreased but failed to reach the baseline completely. Esophageal body function was assessed by giving 5 wet swallows of 5 $\mathrm{ml}$ of water at 30-second intervals. The velocity and amplitude of the contractions were analyzed in the entire esophagus. For the assessment of esophageal motility disorders we used the classification proposed by J. E. Richter (15).

\section{Ambulatory pH monitoring}

Acid-suppressing medications were discontinued 3 days ( $\mathrm{H} 2$ blockers) or 14 days (proton pump inhibitors) before the study. Gastroesophageal reflux was abnormal in patients with an abnormal DeMeester score (normal<14.7). We used the MICRODIGITRAPPER, a pH-meter with a disposable antimony $\mathrm{pH}$ catheter equipped with two sensors spaced $15 \mathrm{~cm}$ apart or the BRAVO Ph-SYSTEM, with radiotelemetry $\mathrm{pH}$-monitoring. Ambulatory $\mathrm{pH}$ monitoring was done by placing a $\mathrm{pH}$ probe 5 $\mathrm{cm}$ above the upper border of the manometrically determined LES. The probes were calibrated in a standard buffer solution at $\mathrm{pH} 7$ and $\mathrm{pH} 1$ both before and after monitoring. The $\mathrm{pH}$ Software Analysis Program was used to record, store, view and analyze gastroesophageal pH data.

A fibreoptic bilirubin catheter (Bilitec 2000, Synectics Medical, Sweden) using Micropore tape (3M, St Paul, MN, USA) was taped to the $\mathrm{pH}$ catheter. The bilirubin sensor was taped adjacent to the proximal $\mathrm{pH}$ sensor.

Patients were instructed to eat three meals per day, and were provided with a list of acid foods to avoid which may interfere with $\mathrm{pH}$ and dark coloured foods to avoid which interfere with bilirubin absorption spectra (a list previously validated in this laboratory). They were asked to finish their evening meal at least $2 \mathrm{~h}$ before retiring to bed, and not to eat or drink again until getting up in the morning.

Gastro-oesophageal acid reflux was defined as a fall in $\mathrm{pH}$ below 4 and bilirubin reflux as an absorbance greater than 0.14 (16). A significant esophageal alkaline shift was defined as having occurred if the pH exceeded 4 (although this is an arbitrary value, it has been the most frequently used threshold value for 
identification of alkaline change). Total, upright and supine per cent times were calculated for oesophageal $\mathrm{pH}<4$, gastric $\mathrm{pH}$ $>4$ and gastric bilirubin $>0.14$ (17-20).

\section{Statistical analysis}

Baseline demographic, clinical, and laboratory characteristics are shown as means and standard deviation for continuous data, and data number and percentage for categorical data. Differences in the means were evaluated by ANOVA for multiple comparisons. The chi-square test was applied to categorical variables. Differences were considered statistically significant at a p-value of $<0.05$.

\section{RESULTS}

Nine hundred and seventy-six functional studies were performed, 707 of which were esophageal manometries, 225 esophageal $\mathrm{pH}$-monitoring, and 44 bilimetries. We divided the patients into three groups: Group 1 consisted of 615 patients (85.9\%) affected with dysphagia; Group 2 consisted of 85 patients (11.9\%) affected with non-cardiac chest pain; and Group 3 of 16 patients (2.2\%) affected with non-cardiac chest pain and dysphagia. In Group 1, 607 patients underwent esophageal manomentry, 147 patients underwent $24 \mathrm{~h} \mathrm{pH}$ monitoring, and 26 underwent 24h-bilimetry. In Group 2, 84 patients underwent esophageal manometry, 73 patients underwent 24h pH-monitoring, and 16 underwent 24h-bilimetry. In Group 3, all 16 patients underwent esophageal manometry, 5 patients also underwent $24 \mathrm{~h} \mathrm{pH}$-monitoring, and 2 also underwent $24 \mathrm{~h}-\mathrm{pH}$ monitoring and bilimetry.

Manometric anomalies were detected in $84.4 \%$ of cases $(p<0.001)$. The most frequent esophageal motility alteration was achalasia, found in $36 \%$ of all patients. The manometric alterations found in Group 1 are summarized in Figure 1. In this group of 615 patients, the most common esophageal disorder was achalasia, found in $41 \%$ of the patients. In Group 2, most of the 85 patients had an abnormal manometry (65.5\%), with the most common alteration being non-specific esophageal motility disorders. In Group 3, the most common esophageal disorder found in the 16 patients was hypertensive dyskinesia $(37.5 \%)(p<0.001)$.

The LES was normal in $45.9 \%$ of patients $(p<0.001)$. In Group 1 , the most common LES alteration was hypertensive LES, found in $50.2 \%$ of the patients. In Group 2, the majority of patients showed no LES alterations (79.8\%). In Group 3, the majority of patients showed no LES alterations (68.8\%) $(p<0.001)$. Most of the patients had a normal UES (83.3\%) $(p=0.005)$. In all three groups the majority of patients, $80.9 \%, 98.8 \%$, and 93.8 , respectively ( $p=0.005)$, showed no UES alterations. In Group 1, the majority of patients showed no acid, biliary or mixed esophageal reflux (64.6\%; 65.4\%, and $84.6 \%$, respectively) ( $p=0.4)$. In Group 2, the majority of patients showed no acid, biliary or mixed esophageal reflux (56.2\%; 81.3\%, and $81.3 \%$, respectively) ( $p=0.06)$. In Group 3, acid reflux was present in $60 \%$ of the

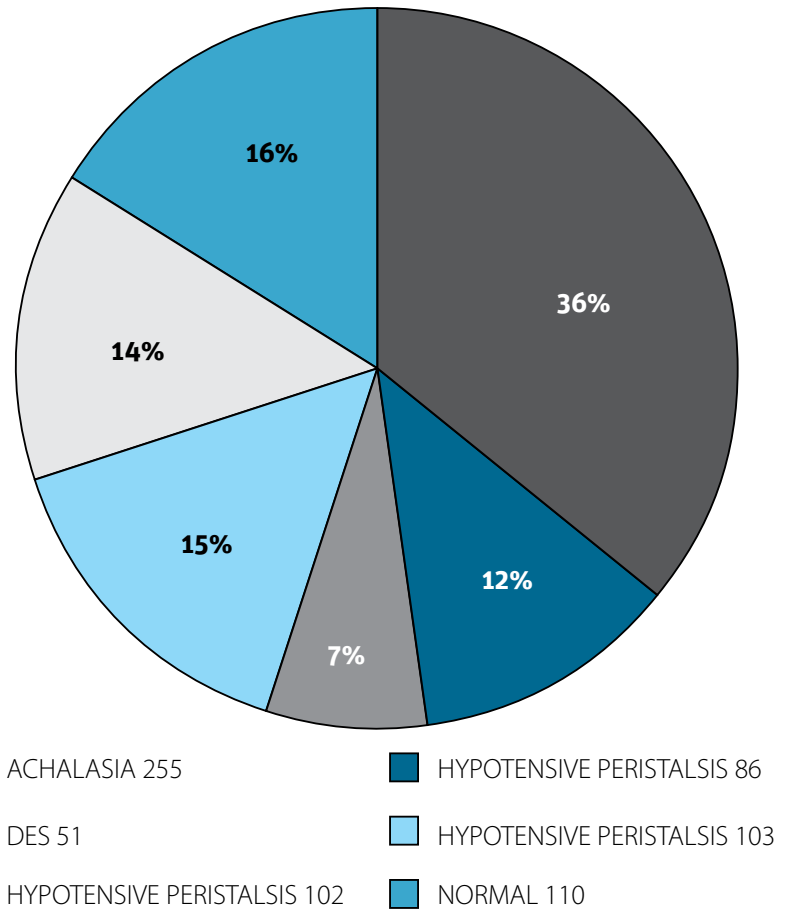

Figure 1. Distribution of esophageal motor abnormalities in all patients.

patients, and biliary reflux in 100\% of the patients, though no patients had acid and non acid reflux $(p=0.8)$. These findings are summarized in Table 1.

\section{DISCUSSION}

Of all the indications for esophageal manometry, dysphagia was by far the most common (86\%). Our results show that most of patients with dysphagia, chest pain, or both, had some type of esophageal motor dysfunction (EMD), which may explain the symptoms. However a significant percentage of patients showed normal esophageal manometry regardless of the referral indication. The study Dekel et al. has shown a high prevalence of normal motility in patients with these symptoms: in this study a total of $70 \%$ of patients referred for non-cardiac chest pain, 53\% for dysphagia and 55\% for both dysphagia and non-cardiac chest pain were found to have a normal oesophageal manometry (21). Our data differ from those of other studies in two important ways: our data was collected from a single tertiary level referral center, and most of these data were collected and analyzed by a single examiner. This may have eliminated some variability.

Most patients with NCCP showed abnormal esophageal motility, and most showed non-specific EMD (NEMD), with normal LES and UES. Achalasia and DES were the least common anomalies. For those patients with dysphagia and NCCP, the most common EMD was hypertensive dyskinesia, followed by DES. Normal LES and UES were also frequent in this group.

Even though DeMeester et al. found that $46 \%$ of patients had chest pain associated with an acid reflux event, as documented 
Table 1. Demographic and clinical characteristics of patients according to esophageal symptoms

\begin{tabular}{|c|c|c|c|c|}
\hline & $\begin{array}{c}\text { Dysphagia } \\
(n=615)\end{array}$ & $\begin{array}{l}\text { Chest pain } \\
\quad(n=85)\end{array}$ & $\begin{array}{l}\text { Mixed } \\
(n=16)\end{array}$ & $\mathrm{p}$ \\
\hline Age (years) & $55.4 \pm 17.4$ & $49.4 \pm 13.5$ & $56.4 \pm 12.7$ & 0.009 \\
\hline \multicolumn{5}{|l|}{ Gender } \\
\hline male & 276 (44.9\%) & $44(51.8 \%)$ & $7(43.8 \%)$ & 0.4 \\
\hline female & 339 (55.1\%) & 41 (48.2\%) & $9(56.2 \%)$ & \\
\hline \multicolumn{5}{|l|}{ Manometry* } \\
\hline normal & 79 (13.0\%) & $29(34.5 \%)$ & $2(12.5 \%)$ & $<0.001$ \\
\hline hypertensive & 65 (10.7\%) & 15 (17.9\%) & $6(37.5 \%)$ & \\
\hline hypotensive & 89 (14.7\%) & $13(15.5 \%)$ & 0 & \\
\hline achalasia & 249 (41.0\%) & $3(3.6 \%)$ & $3(18.8 \%)$ & \\
\hline DES & $45(7.4 \%)$ & $2(2.4 \%)$ & $4(25.0 \%)$ & \\
\hline nonspecific & 80 (13.2\%) & $22(26.2 \%)$ & $1(6.2 \%)$ & \\
\hline Hyatal hernia* & 124 (20.4\%) & 31 (36.9\%) & $3(18.8 \%)$ & 0.003 \\
\hline \multicolumn{5}{|l|}{ LES* } \\
\hline normal & 247 (40.7\%) & 67 (79.8\%) & $11(68.8 \%)$ & $<0.001$ \\
\hline hypertonic & 305 (50.2\%) & $4(4.8 \%)$ & $4(25.0 \%)$ & \\
\hline hypotonic & $51(8.4 \%)$ & $11(13.1 \%)$ & $1(6.2 \%)$ & \\
\hline dyskinetic & $4(0.7 \%)$ & $2(2.4 \%)$ & 0 & \\
\hline \multicolumn{5}{|l|}{ UES* $^{*}$} \\
\hline normal & $491(80.9 \%)$ & 83 (98.8\%) & 15 (93.8\%) & 0.005 \\
\hline hypertonic & $3(0.5 \%)$ & 0 & 0 & \\
\hline hypotonic & $8(1.3 \%)$ & 0 & 0 & \\
\hline dyskinetic & 105 (17.3\%) & $1(1.2 \%)$ & $1(6.2 \%)$ & \\
\hline Acid reflux* & $52(35.4 \%)$ & $32(43.8 \%)$ & $2(40.0 \%)$ & 0.4 \\
\hline Biliary reflux* & $9(34.6 \%)$ & $3(18.8 \%)$ & $2(100 \%)$ & 0.06 \\
\hline Mixed reflux & $4(15.4 \%)$ & $3(18.8 \%)$ & 0 & 0.8 \\
\hline
\end{tabular}

during $\mathrm{pH}$ testing (22), our study did not find a significant association between symptoms and acid reflux. This is due to the fact that only a small percentage of patients underwent $24 \mathrm{~h}$ $\mathrm{pH}$ monitoring.

Kahrilas and colleagues reported that NEMD was documented in $23-55 \%$ of patients with non-cardiac chest pain at a single tertiary referral center (23). Patients with dysphagia had a significantly higher percentage of abnormal esophageal manometry studies when compared with patients with NCCP (87\% versus 64.5\%; $p<0.001$ ). In our study, the most common EMD in patients with dysphagia were hypotensive esophageal motility disorders (achalasia, followed by hypotensive peristalsis). In this group, hypertensive LES and normal UES were common, while DES and hypertensive peristalsis were uncommon.
The significantly high percentage of symptomatic patients with non-pathologic esophageal motility pattern suggests an unclear origin of the disease, with possible neuromuscular implication. These patients may therefore need more detailed diagnostic studies. We evaluated, by means of esophageal manometry, the effects of transcranial direct current stimulation (TDCS) on esophageal mean distal wave amplitude, pathological distal waves and lower esophageal sphincter (LES) mean pressure in patients with GERD (24). We found that the mean distal wave amplitude increased significantly $(p=0.01)$, and the number of distal pathological waves decreased significantly $(p=0.03)$ during anodal TDCS. LES mean pressure significantly decreased during anodal TDCS ( $p=0.05)$. Though preliminary, our data suggest that TDCS can influence cortical control of esophageal motility and reduce pathological motor pattern in GERD patients.

We believe that patients with dysphagia, NCCP, or both, and normal esophageal manometry may be suffering from pharyngo-esophageal motility alteration and should be assessed with further clinical examinations.

This study has several limitations due to the old manometric technique, but this is a retrospective study starting from 1994 when the conventional manometry was the gold standard in the diagnosis of esophageal motility disorders and the examination consisted of 5 wet swallows. Therefore these data could not be complete because some esophageal motility disorders might be underdiagnosed with conventional manometry. Furthermore conventional manometry is not the technique of choice to assess UES dysfunction.

Ethics Committee Approval: Ethics committee approval was received for this study from the ethics committee of Comitato Bioetico A.O.U.P, University of Palermo

Informed Consent: Written informed consent was obtained Peer-review: Externally peer-reviewed.

Author contributions: Concept - R.G., A.I.; Design - R.G., A.I.; Supervision - G.S., S.B., G.G.; Resource - A.I, V.D.P.; Materials - A.I., V.D.P.; Data Collection\&/or Processing - A.I., S.D.G.; Analysis\&/or Interpretation - A.P.L.; Literature Search - R.G., A.I.; Writing - R.G.; Critical Reviews - S.B.

Conflict of Interest: No conflict of interest was declared by the authors.

Financial Disclosure: The authors declared that this study has received no financial support.

\section{REFERENCES}

1. Spieker M. Evaluating dysphagia. Am Acad Fam Physicians 2000; 61: 3639-48.

2. Bass N. The neurology of swallowing. In: Graher M, ed. Dysphagia: diagnosis and management. Oxford, UK: Butterworth-Heinemann; 1997.p.7-36.

3. Ruth M, Månsson I, Sandberg N. The prevalence of symptoms suggestive of esophageal disorders. Scand J Gastroenterol 1991; 26: 73-81. 
4. Dysphagia. In: Griffith's 5 Minute Clinical Consult 2006 (For PDA). Philadelphia: Lippincott Williams\&Wilkins; 2006

5. Galmiche JP, Clouse RE, Bálint A, et al. Functional esophageal disorders. Gastroenterology 2006; 130: 1459-65.

6. Greenslade J, Wyman A. Investigation of dysphagia. Surgery (Oxford) 2006; 24: 89-92.

7. Fass R. Approach to the patient with dysphagia. (UpToDate 2003) Available from: www.uptodateonline.com

8. Dekel R, Pearson T, Wendel C, De Garmo P, Fennerty MB, Fass R. Assessment of oesophageal motor function in patients with dysphagia or chest pain - the Clinical Outcomes Research Initiative experience. Aliment Pharmacol Ther 2003;18:1083-9.

9. Fass R, Achem SR. Noncardiac chest pain: Epidemiology, natural course and pathogenesis. J Neurogastroenterol Motil 2011; 17: 110-23.

10. Eslick GD, Talley NJ. Non-cardiac chest pain: Squeezing the life out of Australian healthcare system? Med J Aust 2000; 173: 233-4.

11. Stahl WG, Beton RR, Johnson CS, Brown CL, Waring JP. Diagnosis and treatment of patients with gastroesophageal reflux and noncardiac chest pain. South Med J 1994; 87: 739-42.

12. DeMeester TR, O'Sullivan GC, Bermudez G, Midell Al, Cimochowski GE, O'Drobinak J. Esophageal function in patients with angina-type chest pain and normal coronary angiograms. Ann Surg 1982; 196: 488-98.

13. Katz PO, Dalton CB, Richter JE, Wu WC, Castell DO. Esophageal testing of patients with noncardiac chest pain or dysphagia. Results of three years' experience with 1161 patients. Ann Intern Med 1987; 106: 593-7.

14. Patti MG, Gorodner MV, Galvani C, Tedesco P, Fisichella PM, Ostroff JW et al. Spectrum of esophageal motility disorders: implications for diagnosis and treatment. Arch Surg 2005; 140: 442-9.

15. Richter JE. Oesophageal motility disorders. Lancet 2001; 358: 823-8.
16. Caldwell MT, Byrne PJ, Brazil N, Crowley V, Attwood SE, Walsh TN. An ambulatory bile re-ux monitoring system: An in vitro appraisal. Physiol Meas 1994; 15: 57-65.

17. Verdu EF, Fraser R, Murphy GM, Blum AL, Armstrong D. The origin of nocturnal intragastric $\mathrm{pH}$ rises in healthy subjects. Scand J Gastroenterol 1995; 30: 935-43.

18. Mattioli S, Felice V, PilottiV, Bacchi ML, Pastina M, Gozzetti G. Indications for 24-hour gastric $\mathrm{pH}$ monitoring with single and multiple probes in clinical research and practice. Dig Dis Sci 1992; 37: 1793-801.

19. Attwood SE, Ball CS, Barlow AP, Jenkinson L, Norris TL, Watson A. Role of intragastric and intraoesophageal alkalinisation in the genesis of complications in Barrett's columnar lined lower oesophagus. Gut 1993; 34: 11-5.

20. Robles-Campos R, Parrilla-Paricio P, Lujan-Mompean JA, Aguayo $J$, Sanchez-Bueno F, Rodriguez-Gonzales JM. Quantification of duodenogastric reflux in gastroduodenal peptic ulcer and in gastric operation patients, using a 24 hour gastric $\mathrm{pH}$ measurement as a quantification technique. Br J Surg 1990; 77: 428-31.

21. Dekel R, Pearson T, Wendel C, De Garmo P, Fennerty MB, Fass R. Assessment of oesophageal motor function in patients with dysphagia or chest pain - the Clinical Outcomes Research Initiative experience. Aliment Pharmacol Ther 2003; 18: 1083-9.

22. DeMeester TR, O'Sullivan GC, Bermudez G, Midell Al, Cimochowski GE, O'Drobinak J. Esophageal function in patients with angina-type chest pain and normal coronary angiograms. Ann Surg 1982; 196: 488-98.

23. Kahrilas PJ, Clouse RE, Hogan WJ. American Gastroenterological Association technical review on the clinical use of esophageal manometry. Gastroenterology 1994; 107: 1865-84.

24. Vigneri S., Bonventre S., Inviati A., Cosentino G., Giglia G., Puma A. et al. Clin Effects of transcranial direct current stimulation (TDCS) on esophageal motility and pathological waves in gastroesophageal reflux disease (GERD) patients. Clin Auton Res 2011; 21: 425-40. 